\title{
Pembelajaran Berbasis Karakter dan Pelatihan Pembuatan Liniment Ektrak Jahe di Madrasah Habibul Badri
}

\author{
Hadi Barru Hakam Fajar Siddiq, Asa Falahi \\ Akademi Farmasi Jember \\ hakamfajar@gmail.com
}

\begin{abstract}
Abstrak
Madrasah Habibul Badri merupakan salah satu madrasah atau lembagapendidikan non formal berbasis keagaman yang terletak di Dusun Calok Desa Arjasa Kecamatan Arjasa Jember. Santri Madrasah Habibul Badri merupakan anak usia 6-14 tahun yang bertempat tinggal dilingkungan madrasah. Dengan demikian, pembentukan karakter individu anak menjadi sangat penting agar anak-anak tersebut menjadi pribadi yang berkarakter secara individu maupun sosial. Kondisi latar belakang ekonomi dan keluarga santri Madrasah Habibul Badri saat ini sebagian besar menggambarkan kelompok status ekonomi menengah ke bawah dengan latar belakang pendidikan orang tua juga rendah. Oleh karena itu, Madrasah Habibul Badri tidak memungut biaya pada santri yang belajar disana. Kondisi tersebut menjadi salah satu sebab tingkat keterampilan dan pemahaman orang tua santri tentang kesehatan masih rendah. Linimentum atau liniment adalah sediaan cair atau kental yang mengandung analgesik dan zat yang memiliki sifat rubefacient untuk menghangatkan, dan digunakan sebagai aplikasi topikal. Jahe memiliki bau yang khas dan rasa panas atau pedas sehingga cocok diformulasikan untuk obat gosok. Liniment jahe mempunyai banyak khasiat dalam bidang kesehatan diantaranya yaitu untuk mengatasi rematik, tulang keropos, asma, stroke, dan menghangat kan badan Hasil program Iptek bagi Masyarakat tentang pembelajaran berbasis yang telah dilaksanakan di Madrasah Habibul Badri melalui metode pembelajaran outbond menunjukkan bahwa santri mengikuti kegiatan tersebut dengan sangat baik, sehingga kegiatan tersebut nantinya akan membantu membentuk karakter yang baik pada santri. Selanjutnya, program pelatihan pembuatan liniment pada Ibu wali santri juga berjalan sangat baik. Pelatihan tersebut diharapkan akan memberikan informasi kepada Ibu wali santri tentang liniment.
\end{abstract}

Kata kunci: outbond, liniment, jahe

\begin{abstract}
Madrasah Habibul Badri is one of the diversity-based madrasas or non-formal education institutions located in Calok Hamlet, Arjasa Village, Arjasa Jember District. Madrasah Santri Habibul Badri is a 6-14 year old child who lives in a madrasa school. Thus, the formation of individual character of children becomes very important so that these children become individuals who have individual and social characteristics. The current economic background and santri family of Madrasah Habibul Badri mostly describe the group of middle to lower economic status with a low educational background of parents. Therefore, Madrasah Habibul Badri did not charge fees for students who studied there. This condition is one of the reasons for the level of skills and understanding of parents of students about health is still low. Liniment or liniment is a liquid or thick preparation that contains analgesics and substances that have rubefacient properties to warm up, and are used as topical applications. Ginger has a distinctive smell and a hot or spicy taste so it is suitable to be formulated for liniment. Ginger Liniment has many benefits in the field
\end{abstract}


of health such as to overcome rheumatism, bone loss, asthma, stroke, and warm the body The results of the Science and Technology program for the community on Habibul Badri based learning through outbound learning methods showed that santri participated in the activity very well, so that these activities will later help shape the good character of the santri. Furthermore, the training program for making liniment for the santri guardian's mother also went very well. The training is expected to provide information to the mother of santri guardians about liniment.

Keywords: Outbond, Liniment, Ginger

\section{PENDAHULUAN}

Madrasah Habibul Badri merupakan salah satu madrasah atau lembaga pendidikan non formal berbasis keagaman yang terletak di Dusun Calok Desa Arjasa Kecamatan Arjasa Jember. Madrasah Habibul Badri didirikan oleh seorang ustad bernama Lutfi. Beliau mendirikan madrasah Habibul Badri karena keinginan anak-anak mengenal agama Islam dengan baik sebagai bekal mereka hingga mati. Madrasah Habibul Badri didirikan dengan dana pribadi dan swadaya masyarakat serta dibantu oleh pemerintah desa.

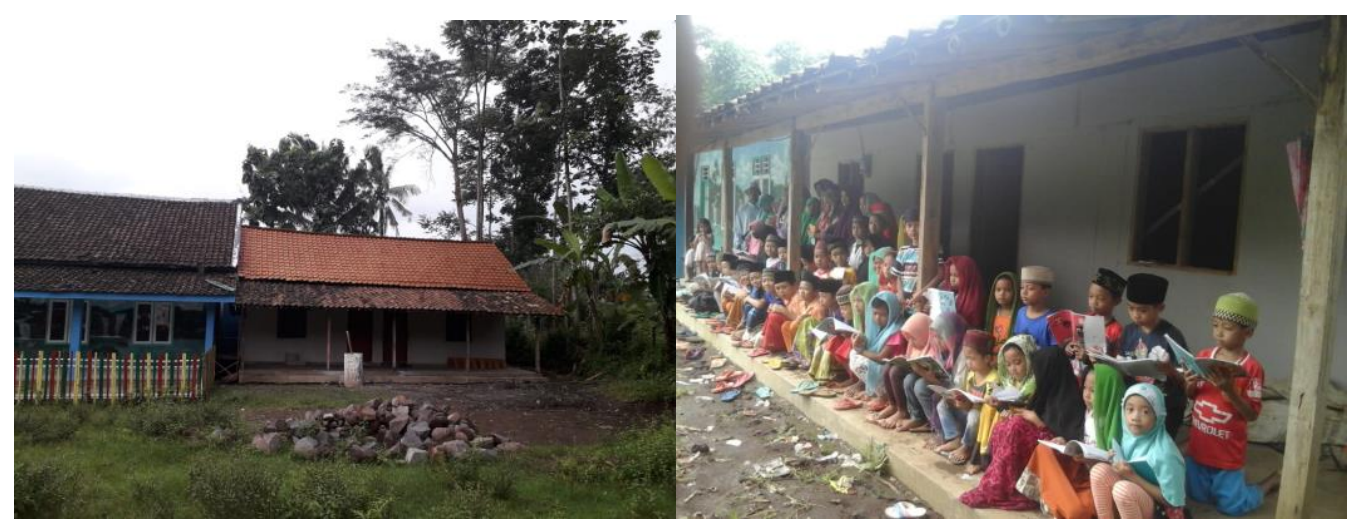

Gambar 1. Madrasah Habibul Badri

Dalam kegiatan pembelajaran di Madrasah Habibul badri dilakukan secara gratis. Santri yang belajar tidak dipungut biaya, begitu pula dengan pengajar (ustadz) tidak ada honorarium. Semua dilakukan dengan ikhlas karena Allah S.W.T. Kondisi tersebut tidak lantas membuat animo masyarakat untuk bersekolah disana menjadi besar, namun diperlukan perjuangan dan tenaga yang besar untuk membuat masyarakat mau menitipkan anaknya disana untuk menuntut ilmu.

Saat ini jumlah santri yang bersekolah di Madrasah Habibul Badri sudah 50 orang dengan rentang usia 6-14 tahun yang bertempat tinggal dilingkungan madrasah. Santri belajar di Madrasah Habibul Badri setiap hari dari jam 14.0016.00 WIB. Pembelajaran di Madrasah hanya seputar pelajaran Agama Islam, seperti kitab kuning, fikih, aqidah, tajwid, dan lain-lain. 
Pemerintah saat ini sedang berupaya untuk melaksanakan pembelajaran karakter dalam pendidikan formal baik tingkat SD sampai perguruan tinggi. Dengan demikian, pelaksanaan program pembelajaran karakter sangat penting terutama di usia anak-anak, sehingga anak-anak akan tumbuh menjadi pribadi yang memiliki akhlak yang baik secara individu maupun social. Kegiatan ini juga perlu di dukung oleh orang tua, sebagai salah satu kunci penting dalam pembentukan karakter anak. Kondisi latar belakang ekonomi dan keluarga santri Madrasah Habibul Badri saat ini sebagian besar menggambarkan kelompok status ekonomi menengah ke bawah dengan latar belakang pendidikan orang tua juga rendah.

Di lain pihak, hirilisasi hasil penelitian merupakan salah satu upaya menerapkan hasil penelitian yang telah dilakukan oleh peneliti kepada masyarakat. Hirilisasi dilakukan agar hasil-hasil penelitian menjadi suatu produk yang dapat dimanfaatkan oleh masyarakat. Khususnya pada bidang farmasi, banyak hasil penelitian yang belum dilakukan hirilisasi menjadi produk yang dapat dimanfaatkan oleh masyarakat, salah satunya adalah produk liniment. Liniment merupakan produk sediaan farmasi untuk pemakaian pada kulit yang dapat berupa larutan alkohol atau berlemak atau emulsi yang terdiridari macam-macam bahan obat yang penggunaannya biasanya digosokkan pada kulit. Linimentum dengan pembawa alkohol atau hidroalkohol berguna dalam hal rubefasien, menghasilkan sakit atau kerja penetrasi yang ringan, linimentum berlemak umumnya digunakan untuk mengurut/memijit. (Rahayu, 2015). Berdasarkan penjelasan tersebut, program ini juga akan melakukan hirilisasi hasil penelitian berupa pembeuatan produk liniment ekstrak jahe kepada ibu wali santri.

\section{METODE PELAKSANAAN}

\section{A. Kerangka Pemecahan Masalah}

Kerangka berpikir untuk memecahkan masalah kegiatan ini digambarkan seperti pada gambar 2. Berdasarkan permasalahan yang muncul disusun alternatife untuk memecahkan masalah. Selanjutnya dari berbagai lternative, dipilih lternative yang paling mungkin dilaksanakan. Berdasarkan kerangka berpikir tersebut, maka metode dalam kegiatan ini adalah sebagai berikut: 

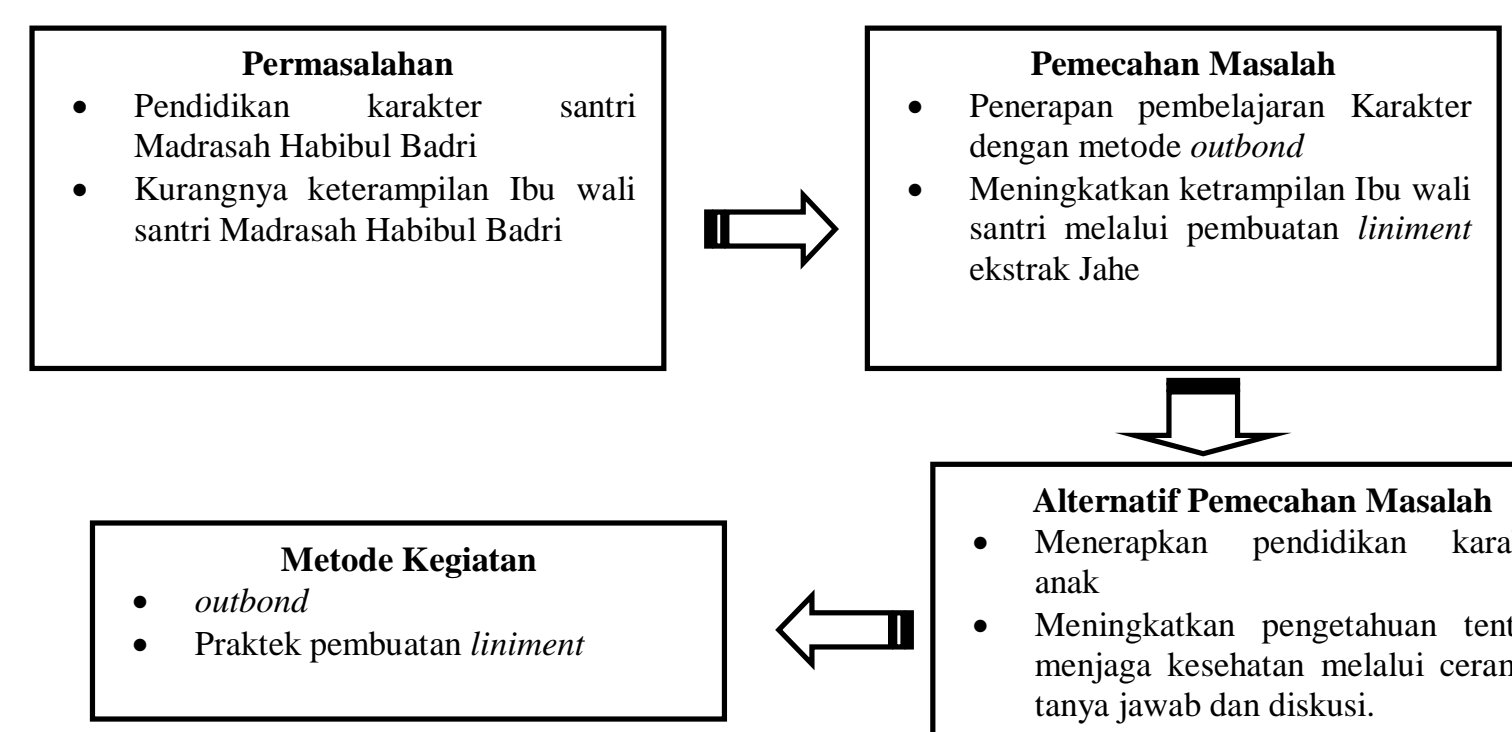

Gambar 2. Bagan Skematis Metode Pemecahan Masalah

\section{B. Realisasi Pemecahan Masalah \\ 1. Caramah dan Diskusi}

Ceramah dan diskusi dilakukan untuk memberikan pemahaman santri tentang pendidikan karakter. Ceramah dan diskusi dilakukan untuk memberikan pemahaman Ibu wali santri tentang hidup sehat serta bagaimana mengolah bahan-bahan alam menjadi produk olahan yang dapat bermanfaat untuk kesehatan dan bernilai ekonomis.

\section{Praktek}

Kegiatan ini merupakan lanjutan dari metode ceramah dan diskusi melalui kegiatan sebagai berikut:

a. Outbond dilakukan dalam penerapan pendidikan karakter bagi santri.

b. Praktek Pembuatan liniment

\section{Keterkaitan}

Kegiatan pengabdian kepada masayarakat melalui program Iptek bagi Masyarakat ini melibatkan instansi Akademi Farmasi Jember dan Madrasah Habibul Badri. Kedua instansi yang terlibat ini mendapat keuntungan secara bersama-sama, antara lain: 
a. Madrasah Habibul Badri sebagai tempat pelaksanaan kegiatan akan menyediakan SDM yaitu santri dan ibu wali santri yang akan dilatih. Dengan demikian, santri dan ibu wali santri akan memeperoleh manfaat dalam hal peningkatan ketrampilan (soft skill) siswa,

b. Akademi Farmasi Jember melalui lembaga Penelitian dan Pengabdian kepada Masyarakat berperan menyediakan dana, sehingga mendukung pelaksanaan dharma ketiga dari tri Dharma Perguruan Tinggi.

\section{HASIL DAN PEMBAHASAN}

\section{A. Pembelajaran Berbasis Karakter}

Kegiatan pembelajaran berbasis karakter dalam program pengabdian kepada masyarakat dilakukan dalam bentuk permainan outbond. Permainan-pernainan yang dilakukan dalam bentuk kelompok-kelompok adalah sebagai berikut:

\section{Mencariteman}

Tujuan dari permainan ini adalah agar seluruh peserta dapat mengenal lebih baik, ciri-ciri fisik maupun sifat-sifat mereka, dan untuk melatih mereka bekerjasama di dalam kelompok. Cara bermain mencari teman adalah sebagai berikut:

a. Peserta di bagi dalam kelompok dengan jumlah yang sama banyak;

b. Kelompok akan berlomba menyusun barisan. Barisan disusun berdasarkan aba-aba pemandu :tinggi badan, panjang rambut, usia dan seterusnya;

c. Pemandu akan menghitung sampai 10, kemudian kedua kelompok, selesai atau belum, harus jongkok;

d. Setiap kelompok secara bergantian memeriksa apakah kelompok lawan telah melaksanakan tugasnya dengan benar;

e. Kelompok yang menang adalah kelompok yang melaksanakan tugasnya dengan benar dan cepat (bila kelompok dapat meyelesaikan tugasnya sebelum hitungan ke 10 mereka boleh langsung jongkok untuk menunjukkan bahwa mereka telah selesai melakukan tugas);

f. Sebelum pertandingan di mulai bisa dicoba terlebih dahulu untuk memastikan apakah aturan mainnya sudah dipahami dengan benar. 


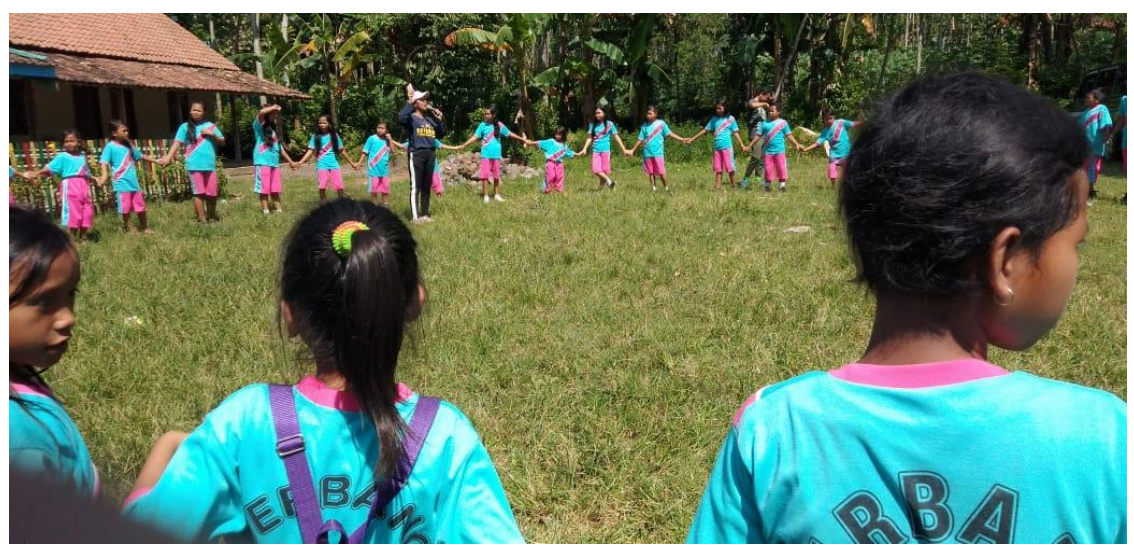

Gambar 4.1 Permainan Mencari Teman di Madrasah Habibul Badri

\section{Karetberjalan}

Permainan ini bertujuan untuk melatih kerjasama kelompok dan kesabaran agar lebih berhati-hati dalam melakukan sesuatu. Saat bermain kita akan bisa langsung melihat wajah teman kita yang berarti secara tidak langsung kita akan meningkatkan kepedulian terhadap teman kita. Alat yang digunakan dalam permainan ini adalah karet dan sedotan. Cara permainan karet berjalan adalah sebagai berikut:

a. Peserta dibagi menjadi beberapa kelompok;

b. Setiap kelompok bediri dan berbaris berbanjar sambil dan setiap orang memegang sedotan dengan mulut mereka;

c. Pemandu menaruh karet gelang di sedotan orang yang berada pada barisan paling depan;

d. Kemudian karet gelang dipindahkan melalui sedotan hingga sampai ke orang terakhir;

e. Kelompok yang paling cepat dan paling banyak memindahkan karet gelang adalah pemenangnya. 


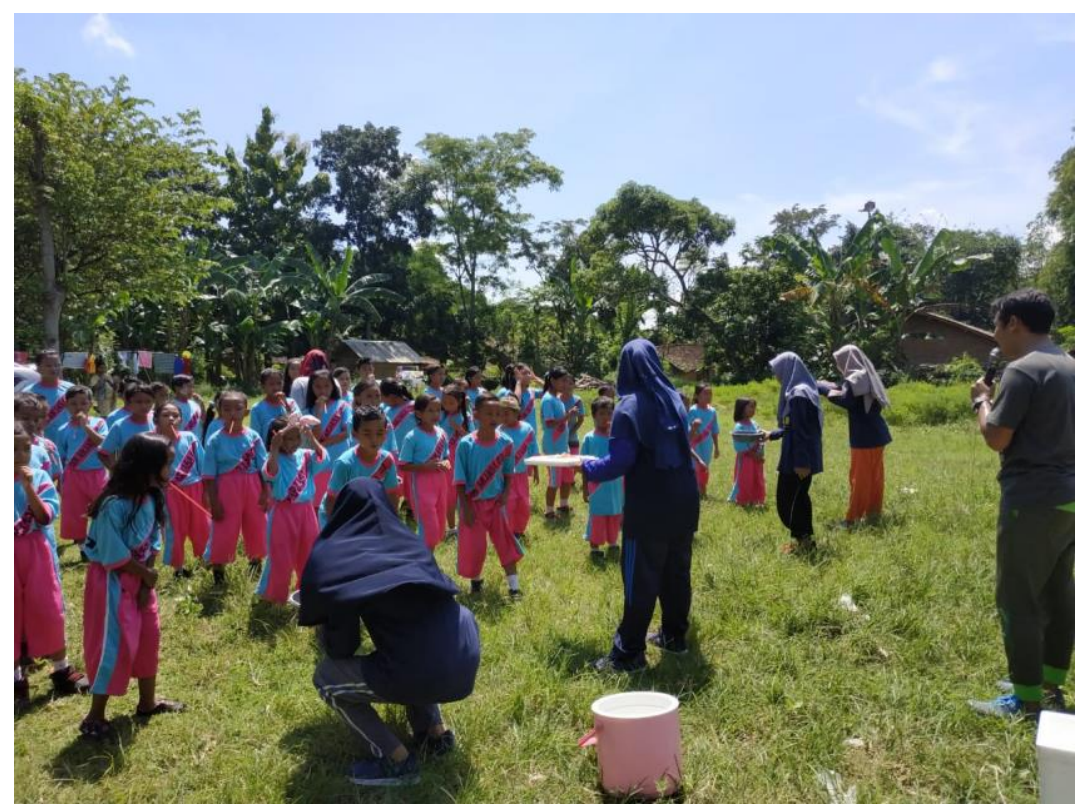

Gambar 4.2 Permaian Karet Berjalan di Madrasah Habibul Badri

\section{Minta tepung}

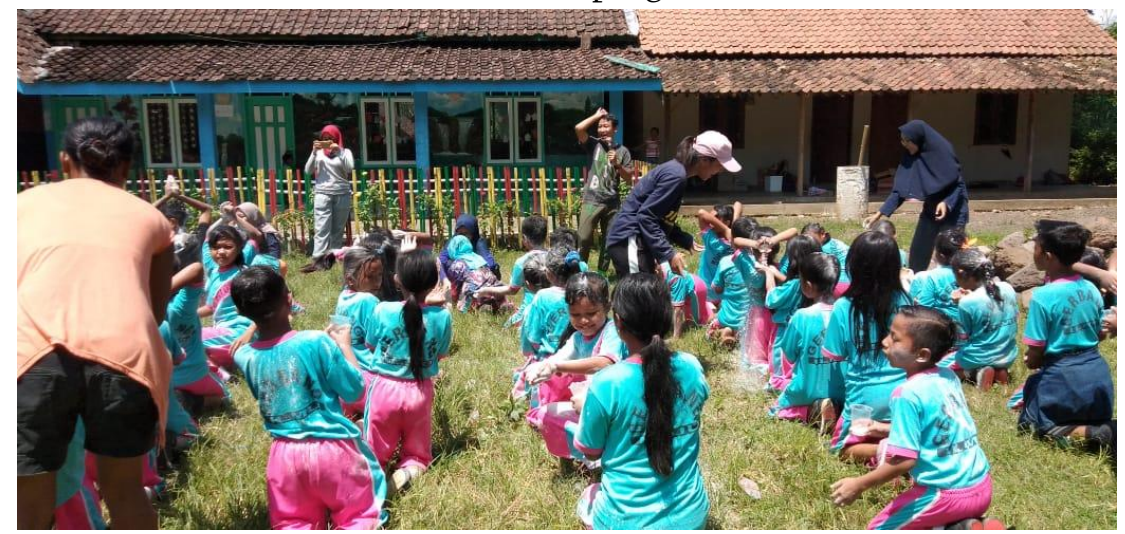

Gambar 4.3 Permaian Karet Berjalan di Madrasah Habibul Badri

Permainan ini bertujuan untuk melatih kerjasama kelompok dan kesabaran agar lebih berhati-hati dalam melakukan sesuatu. Saat bermain kita tidak dapat secara langsung melihat wajah teman kita yang berarti secara tidak langsung kita akan meningkatkan kepercayaan terhadap teman kita. Alat yang digunakan dalam permainan ini adalah tepung. Cara permainan minta tepung adalah sebagai berikut:

a. Peserta dibagi menjadi beberapa kelompok;

b. Setiap kelompok bediri dan berbaris berbanjar sambil jongkok dan setiap orang memegang tepung dengan tangan mereka;

c. Pemandu menaruh tepung pada orang yang berada pada barisan paling depan; 
d. Kemudian tepung dipindahkan melalui tangan yang melewati kepala dengan posisi tetap menghadap depan dan ditangkap oleh orang dibelakangnya, tepung dipindahkan hingga sampai ke orang terakhir;

e. Kelompok yang paling cepat dan paling banyak memindahkan tepung adalah pemenangnya.

\section{Dingin-dingin pintar}

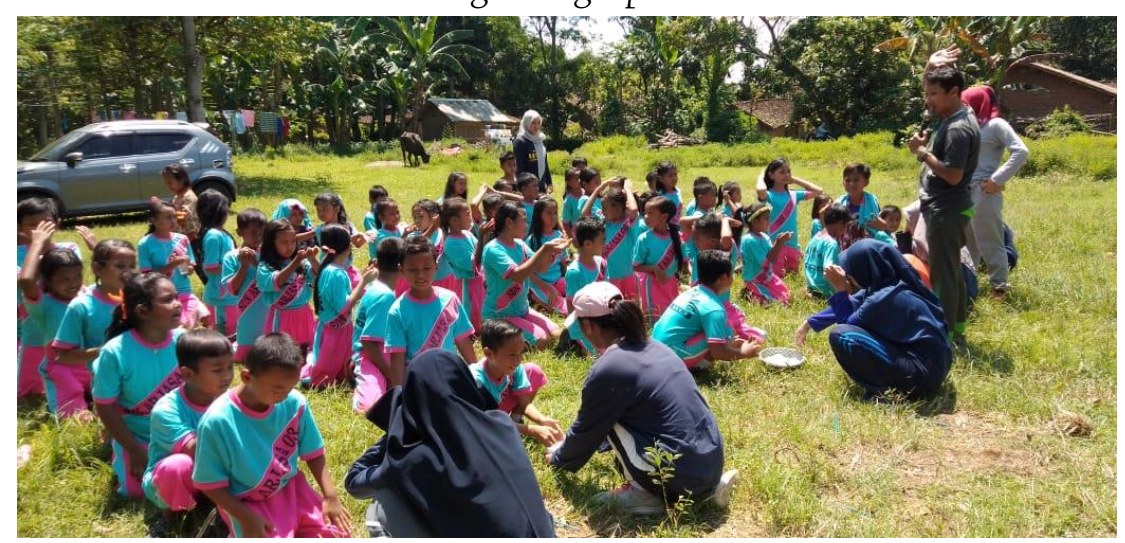

Gambar 4.4 Permainan Dingin-Dingin Pintar di Madrasah Habibul Badri

Permainan ini bertujuan untuk melatih kerjasama kelompok, kesabaran, konsentrasi, dan kemampuan berhitung. Alat yang digunakan dalam permainan ini adalah es batu. Cara permainan dingin-dingin pintar adalah sebagai berikut:

a. Peserta dibagi menjadi beberapa kelompok;

b. Setiap kelompok bediri dan berbaris berbanjar sambil jongkok

c. Pemandu menaruh es batu dengan ukuran kecil-kecil pada orang yang berada pada barisan paling depan dan memberikan pertanyaan tentang penjumlahan;

d. Kemudian es batu dipindahkan melalui tangan kepada orang dibelakangnya setelah menjawab pertanyaan, es batu dipindahkan hingga sampai ke orang terakhir;

e. Kelompok yang paling cepat dan paling tepat menjawab pertanyaan adalah pemenangnya.

\section{Tebakwarna}

Permainan ini bertujuan untuk melatih konsentrasi individu dalam kelompok. Alat yang digunakan dalam permainan ini adalah kertas berwarna. Cara permainan tebak warna adalah sebagai berikut:

a. Peserta dibagi menjadi beberapa kelompok;

b. Setiap kelompok bediri dan berbaris berbanjar 
c. Pemandu memberikan instruksi terhadap hal yang harus dilakukan ketika diberikan kertas berwarna (kertas warna merah berarti maju 1 langkah; kertas warna hijau berarti mundur 1 langkah; kertas warna kuning berarti jongkok);

d. Kemudian pemandu megangkat tangan sambil mengeluarkan kertas berwarna dan tiap kelompok harus mengikuti gerakan sesuai warna;

e. Kelompok yang paling tepat dalam mengikuti gerakan sesuai warna menjadi pemenang.

\section{B. Pelatihan Pembuatan Liniment}

Linimentum atau liniment adalah sediaan cair atau kental yang mengandung analgesik dan zat yang memiliki sifat rubefacient untuk menghangatkan, dan digunakan sebagai aplikasi topikal. Jahe memiliki bau yang khas dan rasa panas atau pedas sehingga cocok diformulasikan untuk obat gosok. Pembuatan liniment di Madrasah Habibul Badri melibatkan orang tua/wali santri Madrasah Habibul Badri. Kegiatan tersebut dilakukan sebagai bentuk edukasi dan penerapan teknologi tepat guna bagi masyarakat, terutama dalam bidang farmasi dan kesehatan.

Peralatan yang digunakan untuk membuat liniment yaitu toples kaca, saringan, batang pengaduk, pisau, sped, botol roll. Bahan yang digunakan untuk membuat liniment yaitu minyak gondopuro, camphora, menthol dan jahe.

Cara membuat liniment jahe yaitu pertama kupas jahe lalu cuci hingga bersih kemudian timbang $100 \mathrm{~g}$ dipotong-potong lalu di geprek, masukkan dalam toples lalu tambahkan minyak gondopuro sebanyak $250 \mathrm{ml}$ diaduk lalu didiamkan hingga berubah warna jadi kuning. Setelah itu disaring, kemudian tambahkan camphora 2 sendok makan di aduk sampai larut. Lalu tambahkan menthol sebanyak 1 1/2 sendok makan aduk sampai larut. Kemudian masukkan dalam botol roll menggunakan sped. Bersihkan bagian luar botol lalu tempel stiker.
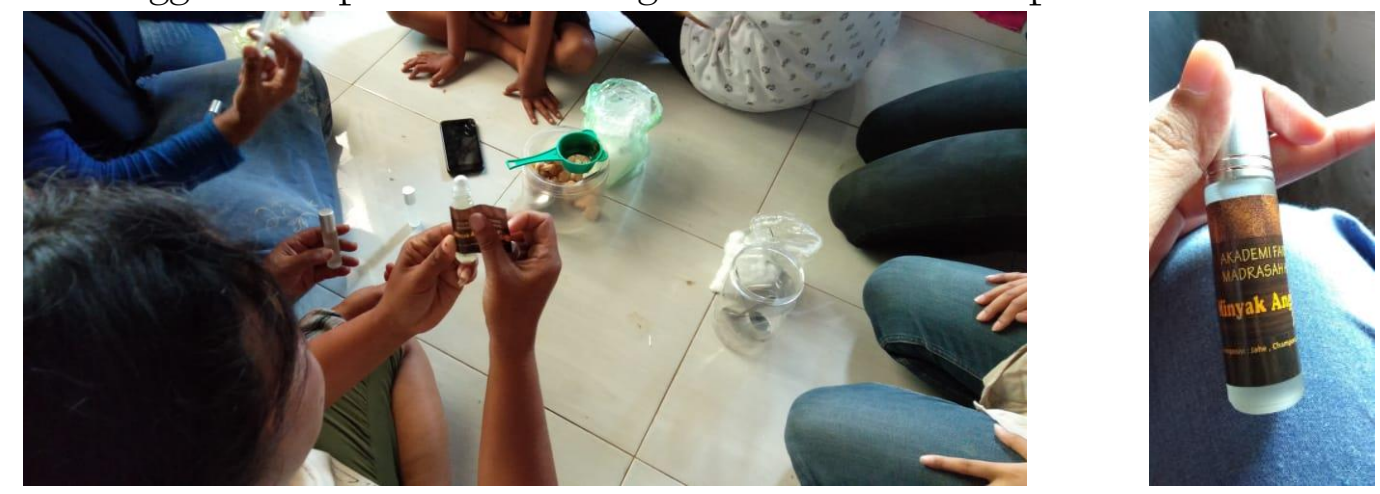

Gambar 4.5 Kegiatan pembuatan liniment di Madrasah Habibul Badri 


\section{KESIMPULAN DAN SARAN}

Berdasarkan hasil iptek bagi masyarakat atau pengabdian kepada masyarakat yang telah dilakukan di Madrasah Habibul Badri, dapat diambil kesimpulan sebagai berikut:

a. Kegiatan pembelajaran berbasis karakter melalui kegiatan outbond di Madrasaha Habibul Badri sangat bermanfaat bagi santri. Karena dapat melatih kekompakan, kesabaran, konsentrasi, dan daya ingat pada individu dan kelompok.

b. Kegiatan pelatihan pembuatan liniment di Madrasah Habibul Badri sangat bermanfaat bagi Ibu wali santri sebagai teknologi tepat guna di bidang farmasi.

Perlu adanya tindak lanjut dan monitoring terhadap pembelajaran berbasis karakter terutama pada anak usia dini. Perlu adanya edukasi dan pelatihan penerapan teknologi tepat guna lainnya di bidang farmasi pada masayarakat

\section{UCAPAN TERIMAKASIH}

Ucapan terima kasih disampaikan kepada Lembaga Penelitian dan Pengabdian kepada Masyarakat Akademi Farmasi Jember dan Kepala Madrasah Habibul Badri Dusun Calok Desa Arjasa, Kecamatan Arjasa Kabupaten Jember.

\section{DAFTAR PUSTAKA}

Rahayu, A. Candrarisna, M. 2015. Perbandingan Aktivitas Linimentum Ekstrak Koral Kelimutu dan Linimentum Ekstrak Daun Lamtoro (Leucaena leucochepala) Terhadap Penyembuhan Scabies Pada Kelinci (Oryctolagus cuniculus). Jurnal Sain Veteriner Vol.33., No. 2. 